\title{
The Role of Prophylactic Antibiotics in the Management of Post Surgical wound Infection
}

\author{
Hanaa Abu Ria, Bosat Olwani, and Altahr Abed Alhamid \\ Assistant professor of Obstetrics and Gynecology, Lecturer of Surgury, Assistant \\ Professor of Urology \\ Faculty of Medicine, Al-Azhar University, Cairo, Egypt
}

\begin{abstract}
Introduction: Prophylactic antibiotics have been shown to be effective in reducing the incidence of febrile morbidity associated with surgical operations. Surgical site infections (SSI's) account for approximately $15 \%$ of nosocomial infections and are associated with prolonged hospital stays and increased costs.
\end{abstract}

Objective: To improve the outcome and to reduce the time stay at the hospital. To determine the independent risk factors for post surgical infection.

To decrease the incidence of post surgical wound infection.

Study Design: An intervention randomized study.

Aim of the work: To evaluate the efficacy of prophylactic antibiotics in reducing the incidence of post surgical wound infection.

Place and Duration: Department of Obstetrics and Gynecology, Department of Surgery and Department of urology, Faculty of Medicine Al-Azhar University from January to June 2011.

Patient and Method: Three hundred patients undergoing surgical operations were enrolled in this study and classified into two groups:

Group1:150 patients received parental prophylactic antibiotics, 1st dose at the time of induction of anesthesia, 2nd dose after $12 \mathrm{hs}$ from the surgery.

Group2: 150 patients received oral antibiotics for five days postoperative.

Results: In this study, Total 300 patients were enrolled,6 patients from group 1 developed wound infection(4\%),39 patients from group 2 developed wound infection(26\%), with prolonged stay at the hospital,2.3 days in group1, and 4.9 days in group 2.

\section{Conclusion:}

The use of prophylactic antibiotics therapy is satisfactory in our surgical environment, this practice would be efficient, cost effective and prevent the emergence of nosocomial infection in developing countries.

Key words: Surgical Sit Infections (SSI's) - Prophylactic antibiotic.

\section{Introduction}

Despite the knowledge about preventing infection and the progress of contemporary surgery, in many hospitals, infection of surgical wound is the most common nosocomial infection (25\%) and the one of the major limiting factor of successful surgery (Boribonhiunsarn et al., 2007\& Ledger, 2006).

Sources of infection may be endogenous, exogenous, or hematogenous.

Most infection occurs due to organisms implanted during the procedure. In obstetrics and gynecological patients the 
site surgical infection are typically caused by maternal coetaneous or endometrial/vaginal flora.( Lofgren et al., 2004).

Modern sterilization techniques, including pre-packed instrument sets for individual surgical procedures, the estlishment of centralized sterile supply department and infection control teams have all contributed to minimize preoperative infection. However despite all these precautions and techniques, the occurrence of this infection has been not abolished completely, with an incidence of $12 \%$ to $25 \%$ even in clean surgical procedures (Chang et al., 2005).

The incidence of SSI depends upon type of surgery, patient risk factors and hospital antimicrobial practices (Gordon et a 2006)

A preoperative site infection (endometrities and pelvic cellulites) is the most common complication of cesarean delivery and hysterectomy. In the absence of antibiotic prophylaxis, approximately $30 \%$ to $40 \%$ of women having an unscheduled cesarean delivery develop endometrities, after a scheduled cesarean, approximately $10 \%$ to $15 \%$ is infected. Approximately one third of women having vaginal hysterectomy have pelvic cellulites if they do not receive prophylactic antibiotics. Prophylactic antibiotics should be recommended for all women undergoing abdominal hysterectomy, women who did not receive prophylactic antibiotics had a higher surgical infection rate (Eason et al., 2004). Wound infection may take one of two forms: an incision abscess or Wound cellulites. Patients with former condition typically have erthyma and warmth at the margins of the wound and purulent discharge from the incision itself. Patients with wound cellulites have an intense erythematous reaction that spreads centripetally from the wound. The affected skin is warm and quite tender to the touch but the purulent

drainage does not exude from the wound (Peipert et al., 2004).

Preoperative antimicrobial prophylaxis has long been advocated in surgical procedure, but recent guidelines and publications show that single dose or two doses prophylaxis is equally effective in elective\&emergency\& clean and clean contaminated surgical procedures (Nisa et al 2005).

Appropriate and prolonged use of antibiotics is a serious problem .It increases the morbidity and mortality of patients and also increases health care cost due to increased antibiotics resistance rate (Her-Young et al., 2005).

To address this problem, we conducted an intervention study in order to evaluate the effectiveness of two doses prophylactic antibiotics in the different surgical procedures.

\section{Patients and Methods}

An intervention study was conducted at Obstetrics and Gynecology Department, Department of Surgery, and Department of Urology at AL-Zahra University Hospital \&AL- Hussein University Hospital from April to June 2011.

Three hundred patients undergoing different surgical operations elective or emergency in the three Departments were classified into two groups:

Group 1: Including 150 patients were received parental prophylactic antibiotics 1 st dose at the induction of anesthesia, and the 2 nd dose $12 \mathrm{hs}$ postoperative.

Group 2: Including 150 patients were received oral antibiotics postoperative.

Exclusion Criteria: All patients with medical disorders (Diabetes-HypertentionAnamia-Blood Disease-and etc. Immunosuppressive patients. Inclusion Criteria:

Male or Female patients.

Infection control methods.

Age and Social class.

Duration of preoperative hospitalization.-

Preoperative hair removal.

Elective operations or emergency.

Duration of operation.

Proper surgical technique.

Any complications during operation.

Duration of hospital stay.

Type of suture materials.

Patients who had established infection prior to operation or had had any antibiotic in the preceding week. 
Research design: This was an intervention randomized control study.

Within 24 hour before surgery, a baseline assessment was performed that included measurement of vital signs (pulse rate, respiration rate, blood pressure, and body temperature), general physical, systemic and gynecological examination. Blood and urine samples were also sent for hematology, blood chemistry, and urine analysis.

Follow up:

Routine postoperative observation was done during hospital stay.

In the second day after operation follow up of patient sheet for hyperthermia (temperature more than 38 degree) and if recurrent as a sign of fever. In the third day of operation (day of discharge of the patient), the patient had the discharge card, the treatment was free of antibiotics in the group 1, and oral antibiotics for five days for group 2.
Febrile morbidity: Temperature of more than 38 degree obtained on 2 or more occasions at least 4 hours apart was early sign of infection.

Signs of wound infection according to Killian et al(2001) are:

*Redness or excessive swelling in the wound.

*Throbbing pain or tenderness in the wound area.

*Generalized chills or fever.

*Pus or watery discharge collected beneath the skin or draining from the wound.

*Foul odor from the wound.

*Red streaks in the skin around the wound, or progressing away from the wound.

*Erythema, induration, cellulitis or purulent drainage.

*Uterine tenderness after $48 \mathrm{hrs}$.

*Offensive or purulent lochia.

\section{Results}

Three hundred patients were enrolled in this study, full history and examination were taken, 142 Obstetric cases, 63 Gynecological cases, 85 surgical cases, and 10 Urological cases.

Table (1) Mean of study variable

\begin{tabular}{|l|l|l|}
\hline & Age(years) & $\begin{array}{l}\text { Duration of hospital stay } \\
\text { (days) }\end{array}$ \\
\hline Group 1 & 38.3 & 2.3 \\
\hline Group 2 & 39.9 & 4.9 \\
\hline
\end{tabular}

The duration of hospital stay was longer in group 2. 
Table (2)

\begin{tabular}{|l|l|l|l|l|}
\hline No. of patients & Low social class & \multicolumn{1}{|c|}{ High social class } & \multicolumn{1}{|c|}{ Female } & Male \\
\hline Group 1 & $144(96 \%)$ & $6(4 \%)$ & $93(62 \%)$ & $112(74.6 \%)$ \\
\hline Group 2 & $139(92.7 \%)$ & $11(7.3 \%)$ & $57(38 \%)$ & $38(25.4 \%)$ \\
\hline
\end{tabular}

Most of the cases were from low social class. Percentage of females was higher than males in both groups.

Table (3)

\begin{tabular}{|l|l|l|l|}
\hline Type of surgery & Total no. of patient & $1^{\text {ST }}$ Group & $2^{\text {ND }}$ Group \\
\hline Gall Bladder & $10(3.4 \%)$ & 4 & 6 \\
\hline Cesarean section & $142(47.3 \%)$ & 72 & 70 \\
\hline T. A. H & $38(12.6 \%)$ & 21 & 17 \\
\hline $\begin{array}{l}\text { Vaginal } \\
\text { hysterectomy }\end{array}$ & $5(1.6 \%)$ & 2 & 3 \\
\hline Laparotomy & $20(6.6 \%)$ & 9 & 11 \\
\hline Hernias & $32(10.6 \%)$ & 14 & 18 \\
\hline Thyroid & $25(8.3 \%)$ & 13 & 12 \\
\hline Breast & $16(5.4 \%)$ & 7 & 9 \\
\hline Genitourinary & $12(4 \%)$ & 7 & 5 \\
\hline
\end{tabular}

Table (4)

\begin{tabular}{|l|l|l|}
\hline $\begin{array}{c}\text { Duration of } \\
\text { operation }\end{array}$ & \multicolumn{1}{|c|}{ Group 1 } & \multicolumn{1}{|c|}{ Group 2 } \\
\hline Within30 min & $85(56.6 \%)$ & $75(50 \%)$ \\
\hline $31-60 \mathrm{~min}$ & $45(30 \%)$ & $50(33.3 \%)$ \\
\hline More than 60 min & $20(13.4 \%)$ & $25(16.4 \%)$ \\
\hline
\end{tabular}

The duration of most of obstetric cases were within $30 \mathrm{~min}$, While the duration of most of gynecological cases were from 31- 60min, and in some of gynecological cases and most of Surgical and urological cases were more than $60 \mathrm{~min}$.

Prolongation of the time of operation, led to increase the incidence of postoperative infection. 
The Role of....

Table (5)

\begin{tabular}{|l|l|l|}
\hline & \multicolumn{1}{|c|}{ Group 1 } & \multicolumn{1}{|c|}{ Group 2 } \\
\hline Elective operation & $90(60 \%)$ & $110(73.3 \%)$ \\
\hline Emergency operation & $60(40 \%)$ & $40(26.7 \%)$ \\
\hline
\end{tabular}

The incidence of post operative infection was higher between patients of emergency operation because there was no time for preoperative preparation especially in obstetric patients with prolonged labor and rupture of membrane.

Table (6)

\begin{tabular}{|l|l|l|}
\hline & Group 1 & Group 2 \\
\hline $\begin{array}{l}\text { Wound infection with } \\
\text { pyrexia }\end{array}$ & $2(1.3 \%)$ & $29(19.3 \%)$ \\
\hline $\begin{array}{l}\text { Wound infection without } \\
\text { pyrexia }\end{array}$ & $4(2.6 \%)$ & $10(6.6 \%)$ \\
\hline
\end{tabular}

The incidence of postoperative wound infection was higher in group 2 and 9 patients from the same group need readmission

For intravenous antibiotics therapy, three patients from them need repeat surgery.

\section{Discussion}

Wound infection remains an important postoperative complication. Its occurrence is associated with readmission, repeat surgery or intervention, prlonged hospitalization and significant clinical and economic consequence (Sadique et al., 2009).

The risk is particularly high in developing countries because of malnutrition, illiteracy, improper surgical technique, substandard sterilization of operation theatres and inadequate or over burdened health facilities. To over come this, prophylactic antibiotics have been recommended by many research workers (Killian et al., 2001).

The objectives are to decrease the incidence of SSI, reduce the effect of antibiotics on normal bacterial flora, reduce adverse effects, use effective \& appropriate antibiotics, minimal change in host defenses, and augment host defense mechanisms at time of bacterial ivation and therapy decreasing the size of inoculums (Sullivan et al 2007)

The benefits to reduce the incidence of SSI, overall the costs and hospital stay (Tita et al 2009).

Several antibiotics have been used in various combinations, single dose or multiple dose regimes given preoperative or over the course of several days. Many 
studies showed that properly administrated prophylactic antibiotics can prevent postoperative infection (Smail et al., 2007\& Oliver et al., 2009).

Appropriate choice of, its timing of administration and proper duration of antibiotics therapy are the factors influencing successful prophylaxis. The timing of prophylactic antibiotics is very important, for prophylactic therapy to be effective; the anti microbial must be present in an adequate concentration while the surgical wound is opened (Costantine et al 2008).

In this study, group 1 received the $1^{\text {ST }}$ dose of prophylactic antibiotics at the time of induction of anesthesia, and the $2^{\mathrm{ND}}$ dose after $12 \mathrm{hs}$ from the operation and group 2 received antibiotic therapy postoperative for five days and the incidence of postoperative wound infection was lower in group 1(6 cases $4 \%)$ in comparison to group $2(39$ cases $26 \%$ and this with correlation with Sadique et al( 2009) in their study on 305 patients undergoing obstetric, gynecological surgical operations received only one single dose of intravenous antibiotics, there was obvious reduction in wound infection, ten patients had postoperative wound infection(3.2\%).

Also the study conducted by Her Young (2005) has shown that prophylaxis antibiotics can reduce the antibiotic cost by $75-80 \%$.Additional cost saving was also found were related to decrease resistance organism outbreaks and decrease postoperative wound infection.

Also Smail (2007) showed that in women undergoing either elective or non elective cesarean section with no signs of infection before operation, the use prophylactic antibiotics has been shown to reduce the risk of endometrities by two thirds to three quarters and a decrease of wound infection justifies the policy of recommending prophylactic antibiotics to women undergoing elective or non elective surgery.

In this study the group 1 received $1^{\mathrm{ST}}$ dose of antibiotics by the anesthiologist during the induction of anesthesia because the timing of prophylactic antibiotic administration is also very important. For prophylactic therapy to be effective, the antimicrobial must be present in an adequate concentration while the surgical wound is opened.The most important factor in pathogenesis of wound sepsis is the presence of bacteria at the time of wound closure thus too early or too late administration of antibiotic therapy cannot produce adequate tissue drug level while surgery is going on and this in agreement with many researchers who suggested that responsibility for prophylactic antibiotic should be assigned to the anesthiologist at the induction of anesthesia(Costantine et al 2008\& Sadique et al 2009 and Vernessa et al 2011 ). SaeTia L et al (2006) showed that antibiotics were effective only if given within4hrs of inoculating bacteria into a wound.

The duration of operation more than 60 min was 20 cases in group 1 and 25 cases in group 2 and the incidence of wound infection was higher between these cases, and this in agreement with Oliver et al (2009) who demonstrated that the risk of postoperative wound infection was Considerably reduced when the operation time was short .In the course of prolonged operation, there was significant tissue devitalization resulting from tissue handling reduced tissue perfusion.

In this study the duration of hospital stay was longer in group2 in comparison to group 1(mean4.1days to 2.3days) and 12 patients from group 2 need readmission and this means increased cost for both patient and hospital, this in correlation with Sadique et al( 2009)who revealed that inappropriate and prolonged use of antibiotics is a serious problem. It increases the morbidity and even the mortality of patients and also increases health care costs due to increased antibiotics resistant rate.

The present study showed no significant difference as regards to the age of the patients in both groups.

The present study the majority of patients was women, and from low social class in both groups and the incidence of wound infection was high between them because lakes of health education, poor nutrition, improper health care illiteracy and bad hygiene. These findings were in agreement with many studies (Nisa et al 2005\& Oliver et al 2009 and Walaa et al 2011). 


\section{Conclusion:}

In conclusion, our study showed that use of prophylactic antibiotics are effective and associated with prevention of serious infectious morbidity associated with surgical operations.

Shorting of the duration of antibiotic prophylaxis may reduce medical cost, resistant microorganism and postoperative complications.

\section{Recommendations:}

-Prophylactic antibiotic therapy must be used in our hospital in elective and non elective operation.

-Increased awareness about health education and infection control method.

Proper preoperative preparation.-

Apply proper surgical technique.-

-Maintenance of standard sterilization techniques of operation room.

\section{References}

Boribonhiunsarn D, lauwahutanont P. (2007) Usage of prophylactic antibiotics in uncomplicated gynecologic abdominal surgery in Siriraj Hospital, 90:1068-73.

Chang WC, Hung YC, TC, Yang TC, CHcn HY, LinCC. (2005) Short course of prophylactic antibiotics in Laproscopically assisted vaginal hysterectomy. J Reprod Med., 50: 524-8.

Costantine MM, Rahman M, Ghulmiyah L, Byers BD, Longo M, Wen T(2008)

Timing of perioperative antibiotics for cesarean delivery: a metaanalysis.

Am J Obstet Gynecol; 199(3):301-306.

Eason EL, Well GA, Garber GE, Hopkins ML. (2004). Prophylactic antibiotics for abdominal hysterectomy: Indication for low risk Canadian women. J Obstet Gynecol Can., 26:1067-72.

Gordon SM. Antibiotic (2006) prophylaxis against postoperative wound infections.

Leve Clin J Med; 73 (Suppl 1):S42-5.

Her-Young SU,Dah-C D, Da-Chung C, MeiFen L,Jah 1,Feng-Yee C(2005). Prospective randomized comparison of single dose vs. one day cefazolin for prophylaxis in gynecologic surgery.Acta Obstet Gynecol Scand, 84:384-8. Killian CA, Graffunder EM, Vincigurra TJ, VeneInfezia RA. (2001): Risk factors for surgical site infections. Infect Control Hospital Epidemlogy, 22:613-617.
Ledger WJ.(2006) Prophylactic antibiotics in obstetric-gynecology: a current asset, a future liability ? Expert Rev Anti Infect. Ther., 4:95764.

Lofgren M, Poromaa I S, Sterndahi J H, Renstrom B.(2004).Postoperative infection and antibiotics prophylaxis for hysterectomy in Sweden. Acta Obstet Gynecol Scand., 83: 1202-7

Nisa M, Tallat N, Hassan I. (2005) Scope on surgical site infection .JPostgrad Med Inst., 19:438-41.

Oliver C Ezechi, Asuquo Edet, Hakim Akinlade, Chidinma V Gab-Okfor and Abeer Herbertson (2009): Incidence and risk factors for caesarean wound infection in Lagos Nigeria. BMC Research Notes, 2:186.

Peipert JF, Weitzen S, Cruickshank C,Story E, Ethridge D, Lapane K. (2004) Risk factors for fibril morbidity after hysterectomy. Obstet Gynecol., 103: 86-91.

Sadique I., Abide S, Aleem S, Anwwar S, Hafeez M, Pasha M.I, ButtF. (2009) Single dose prophylaxis in Obstetrics and Gynecology. Annals., V: 15(4) 167-179.

Sae-Tia L, Chongsomchai C. (2006). Appropriateness of anti-biotic prophylaxis in gynecologic surgery at Srina-garind Hospital. J Med Assoc Thai; 89: 2010-4.

Smail F, Hofmery GJ. (2007): Antibiotic prophylaxis for caesarean section. Cochrane Database of systematic reviews (3) National Instutes of Health.

Sullivan SA, Smith T, Chang E, Hulsey T, Vandorsten JP, Soper D(2007)-

Administration of cefazolin prior to skin incision is superior to cefazolin

at cord clamping in preventing post cesarean infectious morbidity: a

randomized, controlled trial. Am J Obstet Gynecol; 196:455.e1-5

Tita AT, Rouse DJ, Blackwell S, Saade GR, Spong CY, Andrews WW(2009).

Emerging concepts in antibiotic prophylaxis for cesarean delivery: a systematic

review. Obstet Gynecol; 113:675-82.

Vernessa P., Philip.S, Bario, Sharon L. Stein, Koiana Trencheva,.Jeffrey W. Milsom,Sang W. Lee, Toyooki Sonada(2011) Antibiotic regimen and the timing of prophylaxis are important for reducing surgical site infection after elective abdominal colorectal surgery. Surgical Infection., 12(4) 225-260.

Walaa H. Ibrahim, A.M. Makhlouf,Mervet A.Khamis,and Entisar M.Youness.(2011):Effect of prophylactic antibiotics (cephalosporin versus Amoxicillin) on preventing post caesarean section infection, Journal of American Science.,1,7(5)178- 187. 


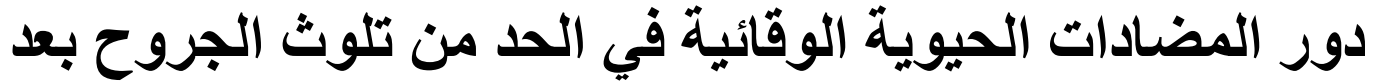 العمليات الجراحية في الية
}

\author{
هناء أبو ريا ، بساط علواني ,الطاهر عبد الحميد
}

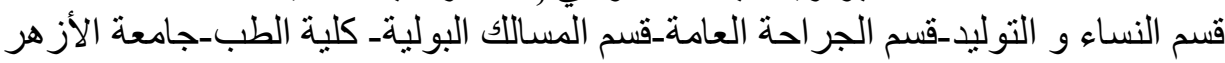

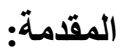

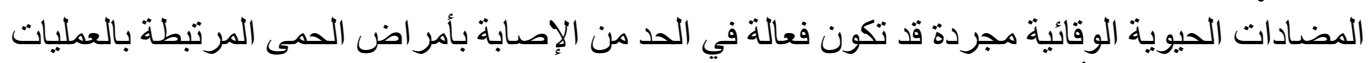

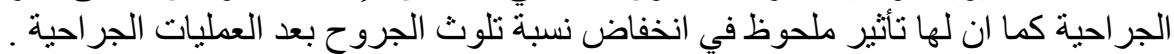

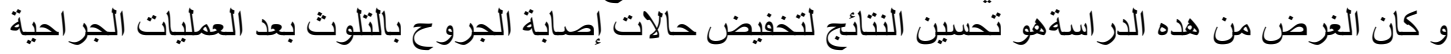
ولتقليل وقت الإقامة في المستشفى و ايضا معرفة.عو امل الخطر التي تؤدي الي التلوث.

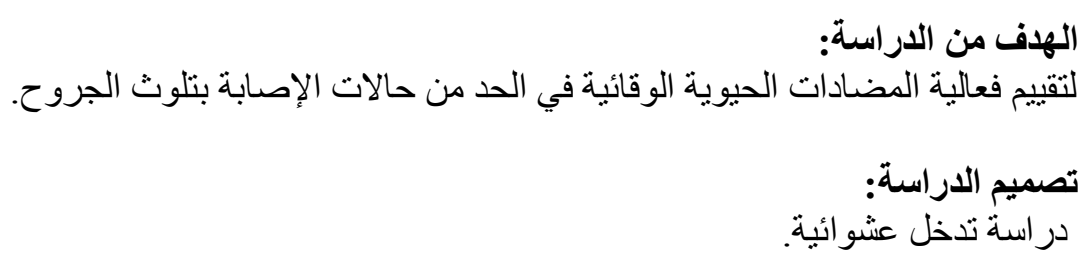

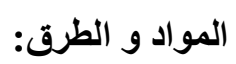

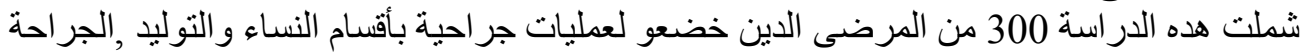

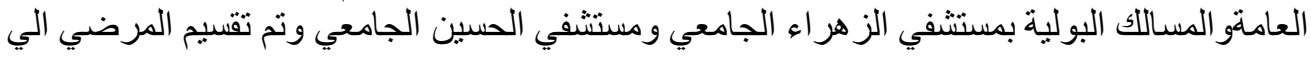

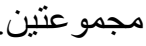

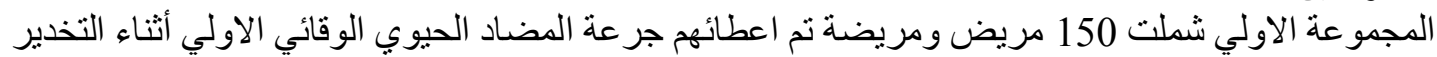

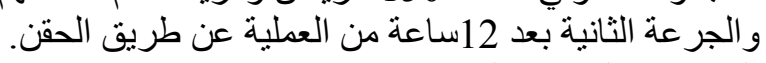
المجموعة الثانية شملت بعد 150 مريض من مريضة مريضة تم اعطائهم جر عة المضاد الحيوي بعد العملية لمدة 5أيام عن طريق الفم.

كانت نسبة التلوث و الاصنابة في الجروح اقل بشكل ملحوظ فى المجمو عة الاولي كما كانت ايضا فترة الاقامة النتائج:: في المستثفي اقل من المجموعة الثنانية.

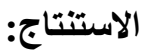

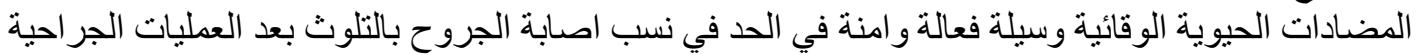
و هو يؤدي الي تكلفة اقل للمريض وللمستشفي وهو عنصر فعال أيضا في مكافحة العدوى في المستشفيات. 